\title{
The Case Study Technologies as the Means of Competency Building Approach Realization in Higher Education of Russia
}

\author{
Albina R. Abdrafikova ${ }^{1} \&$ Ekaterina A. Konopatskaya ${ }^{1}$ \\ ${ }^{1}$ Institute of Philology and Intercultural Communication, Kazan (Volga Region) Federal University, Kazan, \\ Russia \\ Correspondence: Albina Rinatovna Abdrafikova, Institute of Philology and Intercultural Communication, Kazan \\ (Volga Region) Federal University, Kazan, Russia. Tel: 007-917-394-5089. E-mail: albina112000@yahoo.com
}

\author{
Received: September 15, 2014 Accepted: October 21, 2014 Online Published: November 19, 2014 \\ doi:10.5539/elt.v7n12p94 URL: http://dx.doi.org/10.5539/elt.v7n12p94
}

\begin{abstract}
The problem of increasing education efficiency in Russian high school under the condition of well-organized educational process with using "Case-study" technology is considered in the article. The article is devoted to the methodology of case study, and especially its implementation in Kazan Federal University, the Institute of Philology and Intercultural Communication.

The experiment was held in two groups (experimental and control) diagnosing communicative, social, occupational and educational cognitive motives and motives of self-actualization, avoiding failure and prestige. The study was conducted in such disciplines as "English Language", "Training and education in the field of foreign languages". To measure the number of observed qualities of student's personality the diagnostic technique level of formation of students learning motivation was selected. The resulting figures revealed a positive trend from the use of case technology in the classroom with students.
\end{abstract}

Keywords: competency building approach, educational cognitive competence, training, case-study technology

\section{Introduction}

The turn of the century visibly symbolizes the transitory nature of the current era. The humanity today is undergoing a series of deep transformations, changing the face of civilization as a whole, due to the rapidly reaching the transition from an industrial society to a post-industrial society and information, in which the processes of creation and dissemination of knowledge are the key ones. These processes are to a large extent based on the use and development of the educational system. The growing demand for higher education worldwide, along with global expansion of telecommunication technologies, have given online distance education a potential world-wide reach for institutions in many countries (Sadykova, 2009). The content of education is the most important component of the educational system and, accordingly, the main purpose of the planned changes in it. Organizational-administrative, economic, legal reforms, for all its importance, are the same conditions and mechanisms of the output to a new quality of education, and the goal of it is the elaboration and implementation of the new curriculum.

\section{Literature Review}

Infusion of personality with mentality is a supreme target of education. Mentality is the highest level of culture: it represents deep foundations of world view, world vision and behaviour of a man. It is mentality which determines specific deeds of people, their attitude to different social existence (Mukhametshina \& Galimullina, 2014). Nowadays, a modern man is not enough subjected to knowledge, the society needs metaknowledge and skills. A person with the ability to implement complex cultural-oriented types of actions should be able to answer the following questions: "What do I want?", "What can I do?", "Who am I?" In this situation, the goals of education are changing. Theoretical in nature and encyclopedic knowledge, were the main aims of the educational process, now they have become the means to achieve them. In other words, Russian education needs a shift in emphasis from the knowledge-based approach to the competence-based one. Competence-based approach focuses on the construction of the learning process according to the results of education, i.e. what the learner will know and will be able to use.

Strategy and modernization of higher education raises the competence approach as one of the most important 
conditions for the update of the educational process. This approach has become a leading company in the development of the whole world of education and is linked to the need to strengthen the orientation of education to the changing conditions of society, especially labor. What has changed? The speed of information flow, the speed of technical and scientific progress, and the speed of human adaptation to working conditions remained the same, individually conditioned.

The idea of competence-based approach in education as a principle of education are considered in Davydov and Khutorskoy (1996), Shadrikova (2000), Zimnya (1992), Krajewski (2003) and others. In the process of learning and acquisition using competence-based approach, the teacher contributes to a learning-cognitive competency in students. Hutorskoy characterizes them as a set of competencies in the field of self-learning activities, including elements of the logical, methodological, general scientific activities, correlated with real objects (Hutorskoy, 1996).

\section{Methods}

One of the ways to apply the theory in real life effectively, in dealing with the emerging problems is the decision taken in specific situations or contingency management training as well as training on the example of solving a particular situation, which is case-study itself. The baseline characteristic of the concept of competence is the degree of formation of a single specialist body of knowledge, skills, abilities and experience to ensure the implementation of professional activities.

Just yesterday, talking about the integrity of the educational environment was not possible. Firstly, the structure of the educational environment in higher education was clearly "skewed" towards the acquisition of theoretical knowledge, and research has shown that the period when knowledge becomes obsolete by $50 \%$ consists in five years for today's workers (Hutorskoy, 1996). Secondly, the skills obtained by students during laboratory work, problem solving, are not integrated into the production activity that have obviously hindered their use in the work. And only with the transition to a two-level training of higher school has become the priority direction of transformation of basic knowledge in professional development. Thus, a diagnostic method was selected and experiment was held to assess communicative, social, occupational and educational cognitive motives of students.

\section{Studying the Question}

Case is a practical situation, which contains some of the problems. In English case means a particular situation, and case-study - this is a training event. Its content and possible solutions should be analyzed and discussed together: students and a teacher. Educating someone on a specific case gives person wisdom that allows you to envision the future and act in the way the future works on him. The classic definition of "case - is a description of a business situation, for example, among responsible managers, a description including the followed situation, facts, opinions, judgments, which are usually based on the practices and decisions of managers." Andrew Towle adds: "... case-catalyst accelerating the learning process by bringing in his experience" (Neverovich, 1998). In addition, case-study is a set of conditions and obligations, describing very concrete realities in a company within the reviewed period. Case-study provides a management problem and typically includes information about the objectives, financial condition, and the relationship between management and production staff of market conditions, competitor activity and other influences of the environment. Case is also a written presented description of the conditions of life of the organization, group of people or of the individuals orienting students to the formulation of the problem and explores options for its solutions (Karimov, 1995). A case contains comprehensive information about what is going on, who takes part in it, what results must be received? There's just one answer to the question left unanswered that is how? How can we achieve this goal and get the required result? Thus, the participant should solve this case, like a math problem. Case-it's always modeling a life situation. Case allows us to consider the problem from different perspectives. That decision, which the member of the group comes to can serve as a reflection of the level of competence and professionalism of the participants, as well as a real solution to the problem. Cases are good because they are immersed in the participant business processes, while the participant is sitting behind a desk. Usually cases are not the only right decision.

The leading role in the extension of the case-study method belongs to the Harvard Business School. The case-study method was first used at Harvard Business School in 1921 and still is the leader of Harvard "case-industry" around the world - his teachers write 700 high-quality cases per year. Recently the learning method is widely used in the world of management and marketing. Besides Harvard Business School we can point out one more tradition of using a particular situation - the Manchester's one. They describe the situation more briefly but the decision is fundamentally open and generated during group discussions. Relying on the use of the situational training one more famous university in North America takes its floor-the University of 
Western Ontario (Canada). Teachers from Europe travel to the United States "to adopt" the specific character of "case-education."

Case plays an important role in the formation of business students - schools, so that all business schools indicate what part of the training time is allocated to case-study, for example, in Wharton-that's $30 \%$ of teaching time. In the School of Business the University of Chicago the amount of cases used there reaches $25 \%$ of training time, and the business school at Columbia University - 40\%. The ordinary student examines 700 cases while studying at Harvard and spends $90 \%$ of training time on the analysis of specific situations.

Using situational approach in learning helps to reduce the gap between the theory and practice and to develop the students' following skills:

$>$ Evaluate situation;

$>$ Select and share key information;

$>$ Regularly form queries;

$>$ Identify the challenges and opportunities;

$>$ Prognoze the development of the situation;

$>$ Adopt decisions under uncertainty and respond to criticism creatively.

Thus, the teachers' aims are as follows:

$>$ Identify the practical classes to be carried out using this method;

$>$ Choose the appropriate material;

$>$ Think over the direction of the conversation or discussion in the classroom;

$>$ Generalization, an explanation and a reminder of the theoretical aspects of the discipline.

The students' tasks are the following:

$>$ Solve the task set before them;

See the reaction to your decisions, on their optimality;

$>$ Realize that hasty decisions increase the risk in matters of the enterprise organization.

All the work on case-study method can be divided into three phases:

1) Before classes

2) While classes

3) After classes.

Table 1 . The work on case-study method

\begin{tabular}{|c|c|c|c|}
\hline Phase of the work & & Actions of the teacher & Actions of the student \\
\hline \multirow{3}{*}{ Before classes } & 1. & Selects material for the case study; & $\begin{array}{l}\text { Getting the case and the list of the required } \\
\text { references; }\end{array}$ \\
\hline & 2. & $\begin{array}{l}\text { Defines primary and secondary } \\
\text { materials; }\end{array}$ & Individual work of a group with a case; \\
\hline & 3. & $\begin{array}{l}\text { Developing a plan or script of the } \\
\text { classes; }\end{array}$ & Preparation for the practical classes; \\
\hline \multirow{3}{*}{ While classes } & 1. & $\begin{array}{l}\text { Organizes the preliminary case } \\
\text { discussion; }\end{array}$ & $\begin{array}{l}\text { Working out the options of the task solution } \\
\text { and the analysis of the suggested decision; }\end{array}$ \\
\hline & 2. & $\begin{array}{l}\text { Dividing groups into mini ones and } \\
\text { choosing the leader; }\end{array}$ & $\begin{array}{l}\text { The analysis of another decisions and } \\
\text { recommendations; }\end{array}$ \\
\hline & 3. & $\begin{array}{l}\text { Providing mini groups, if necessary, } \\
\text { with additional information; }\end{array}$ & The final decision; \\
\hline \multirow{3}{*}{ After classes } & 1. & Evaluation; & Writing a final report. \\
\hline & 2. & The analysis of decisions taken; & \\
\hline & 3. & The evaluation of decisions taken. & \\
\hline
\end{tabular}


The case-study method's aim is to train students to solve problems, but not to transfer knowledge. Cases are also an important step towards building partnerships between universities and enterprises. "To learn how to drive a car, you need a long lecture on the device of an internal combustion engine, you need to practice driving with an instructor". This statement reflects the essence of this method that is used in training of almost all business schools to teach future managers to apply theoretical knowledge in practice.

The most important is that case-study method promotes the ability to analyze a situation, evaluates alternatives, and instills solution to practical tasks. Cases are very close to simulation games, because simulation games are the objectives of the situational analysis diagnostics. Assessment and forecast are the games' products. Cases differ from the habitual ones for our students that cause many difficulties. The thing is in classical training schools, universities where there is a clear question, the formula for the solution, and one answer. It interferes with the student to focus on the correct perception of the case. Even in business there is not always one correct solution. Classes engaged in the analysis of the cases are focused on the use and practical application of the knowledge gained during the theoretical training and skills based on previous practical experience of students (Mayer, 1996).

The advantages of cases are:

1) Allow to evaluate the candidate for employment more accurately with the standard use of questionnaires or interview;

2) Allow to reveal the creative (leadership) and other potential of the employee during the validation. What potential will be revealed depends on the content of case studies and their objectives;

3) Model the problem situation, in which participants learn. Thanks to these cases are indispensable in training and development;

4) Allow us to find a new solution to the real problem, see the situation in a new way, or to bring a new vision to the authority.

Taking into account everything mentioned above, it may be noted that students develop the ability to analyze the situation, evaluate and choose the best option for its execution.

Examples of possible educational goals of case-study method are the following:

$>$ to acquire knowledge,

$>$ to develop general ideas,

$>$ to understand methods,

$>$ to acquire skills of using this method, concept and knowledge,

$>$ to acquire skills of analyzing complex and unstructured problems,

$>$ to acquire skills of development and implementation of action,

$>$ to develop skills of listening attentively,

$>$ to develop specific relationships (responsibility for your actions, taken decisions),

$>$ to develop the communication skills,

$>$ to develop particular mind qualities,

$>$ to generalize and work out successful concepts.

The script of working with a case can be represented as follows:

Phase 1: Students' work begins with an introduction to the situational problem. As a result, each student should have a holistic impression of the content of a case. Introduction with a case ends with a discussion.

Phase 2: A teacher assesses the degree of the material acquisition, summarizes the discussion and announces the work program. Distribution of topics can be made by a teacher, based on the willingness of each subgroup.

Phase 3: A final stage.

Case-study may be used in many disciplines, such as information technology, management, foreign languages teaching and other disciplines, but it is necessary for every teacher to be creative in their work, learn how to organize independent work of students, search for the truth and be self-critical to perceive conflicting ideas, be able to analyze and design the activities, be prepared for continuous professional growth and the acquisition of new knowledge, the desire to have a stable self-perfection. The main priority task of the teacher is to determine 
what practical lessons can be carried out by this method. The role of the teacher in the classroom is correcting and directing. The teacher makes a synthesis and analysis of the issued decisions, coordinates the discussion on the problem. Using the case-study method implies a fairly well-trained teacher.

Case technology is now considered to be a multifaceted: a way of motivating and encouraging students to active cognitive activity. And, in addition, may act as a means of control and self-control of professional and subject knowledge and skills.

As part of the solution to the problem of improving the efficiency of learning a foreign language (English) in higher educational institutions, we used a technology called "Case Study." When forming a foreign language communicative competence the use of this technology has a positive impact on the development of students' professionalization, namely contributing to their maturation that forms an interest and positive motivation for learning, reveals creativity, attaches to research, teaching work in a team and contributes to a friendly atmosphere in the classroom.

The study was conducted with the third year students studying in the direction of Teacher training preparation: foreign language and second language. The experiment involved two groups. Group A (experimental) - 32 people and group B (control) - 31 people. In the first group the subjects as "English language" and "Training and education in the field of foreign languages" were used, accompanied by the active use of case-study technology, in the second group sessions were held without the use of this technology.

To measure the number of pointed qualities of student's personality a diagnostic technique level of formation of learning motivation of students was selected, namely adapted a technique developed on the basis of a questionnaire by Reana (1999) and Yakunin (2001). There were also used techniques that characterize the motives teachings marked by Leontiev (2002) and Badmaeva (2004). The purpose of using this technique was the diagnosis of communicative, social, occupational and educational-cognitive motives, as well as the motives of self-actualization, avoiding failure and prestige. The obtained results allow us to assert about the low level of formation of students' motivation on the marked characteristics of the diagnostic phase of the experiment in the experimental and control groups.

On the forming stage of the experiment in the classroom in group A we actively used a case-study technology. Students had to analyze a given situation, to explore the possible causes of its occurrence, to answer the questions, suggest correction methods and solutions to the situation. For example, on the training courses on methods of teaching a foreign language to the students the following situation was posed between a teacher and a student: a teacher working on the formation of coherent speech of the child. The theme of the lesson "Making the story on a series of the scene pictures." The teacher puts a child in front of the plot pictures and begins to read the story, then asks the child to recall a sequence of images. During the lesson the teacher notices that a child cannot properly lay out the images and make up a story.

After the completion of studying "English language" and "Training and education in the field of foreign languages" for ascertaining stage of the experiment we had been re-allocated promoted measured personality traits of the student in the control and experimental groups (Figure. 1) (Fahrutdinova, 2012).

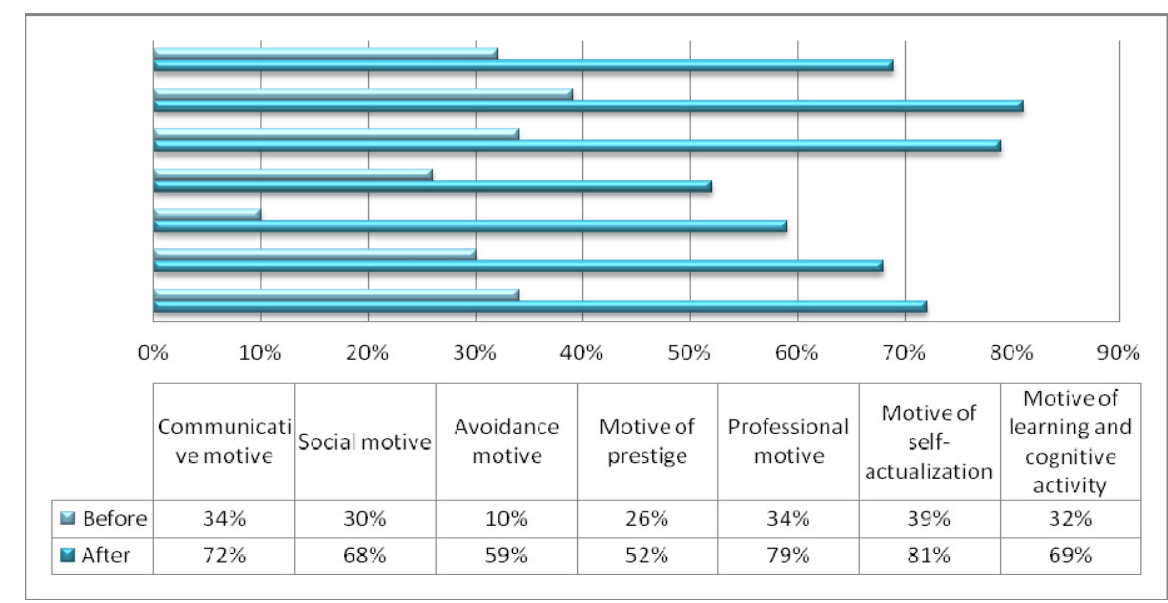

Figure 1. The distribution percentage of the responses of students in Group A at the level of formation of selected qualities of the person, $\%$ 
The data revealed a positive trend from the use of case-study technology in the classroom with the students. Key personality traits, namely motives teaching, communicative, social, occupational and educational-cognitive motives have increased in percentage terms.

\section{Conclusions}

It seems that the Russian training programs should contain advisably $25-30 \%$ on average to the analysis of particular situations. There is no a single standardized scheme. The more important here is to follow the inner principles of specific situations, to initiate self - learning of students forming their own vision on problems and their solutions, the development of the ability to debate and discuss the situation with their peers, teachers. From this point of view, along with the traditional, classic analysis of the situation in small groups and subsequent presentation to a general audience it can be recommended for a wide distribution in the Russian training programs, the independent and individual written analysis of situations with the following discussion in the audience. Such written analysis of situations demonstrated their success as one of the stages of the final exam within the President's programme of management training.

The main thing that the Russian practice of training based on specific situations could pass from the stage of development to the development of professionalism.

\section{Acknowledgements}

The work is performed according to the Russian Government Program of Competitive Growth of Kazan Federal University.

\section{References}

Badmaeva, N. C. (2004). The influence of motivational factors on the development of mental abilities. Ulan-Ude, $\mathrm{U}$ : Knowledge.

Baryshnikov, N. V. (2002). Learning parameters of intercultural communication in the secondary school. Foreign languages at school, 7, 28-32.

Fahrutdinova, R. A., \& Konopatskaya, E. A. (2012). Creating common cultural competencies of students in the multicultural environment of the university in the process of training (for example, the course "Methodology of training and education in the field of foreign languages"). Kazan, K: "Astoria \& C".

Karimov, I. A. (1995). Uzbekistan on ways to deepen economic reforms. Tashkent, T:Uzbekistan.

Klarin, M. V. (1994). Innovative models of learning in foreign educational quest. Moscow, M: Arena.

Koulter, D. (1995). Education by specific situations in Russia. Association of Management Development. Management, 1, 8-11.

Mayer, R. (1996). How to conduct a seminar successfully. Berlin: German Foundation for International Development.

Mukhametshina, R. F., \& Galimullina, A. F. (2014). Inculcation of Bimental Personality in Context of Cultural Dialogue (As Exemplified by Tatarstan Schools). Middle-East Journal of Scientific Research, 20(12), 2135-2138. http://dx.doi.org/10.5829/idosi.mejsr.2014.20.12.21108

Neverovich, S. D. (1998). Game training methods. Moscow, M: High School.

Sadykova, G., \& Dautermann, J. (2009). Crossing cultures and borders in international online istance higher education. Journal of Asynchronous Learning Networks, 13(2), 89-114.

Smolyaninova, O. G. (2000). Innovative technology training students on the basis of case-study. Innovations in Russian education: A collection. Moscow, M: HEO.

Zeer, E. F., Pavlova, A. M., \& Simanyuk, E. E. (2005). Modernization of vocational education: Competence-based approach: Textbook. Moscow, M: Moscow psychological and social institution.

Zhukov, U. M. (1998). The effectiveness of business communication. Moscow, M.: Knowledge.

\section{Copyrights}

Copyright for this article is retained by the author(s), with first publication rights granted to the journal.

This is an open-access article distributed under the terms and conditions of the Creative Commons Attribution license (http://creativecommons.org/licenses/by/3.0/). 